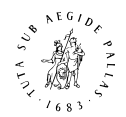

TIME

B R I L L

Timing \& Time Perception 0 (2013) 1-30

brill.com/time

BRLLL

\title{
Time, Emotion and the Embodiment of Timing
}

\author{
Sylvie Droit-Volet ${ }^{1, *}$, Sophie Fayolle ${ }^{1}$, Mathilde Lamotte ${ }^{1}$ and Sandrine Gil ${ }^{2}$ \\ ${ }^{1}$ Blaise Pascal University, Laboratoire de Psychologie Sociale et Cognitive, CNRS UMR \\ 6024, 34 avenue Carnot, 63037 Clermont-Ferrand, France \\ ${ }^{2}$ University of Poitiers, CNRS UMR 7295, Poitiers, France \\ Received 12 March 2013; accepted 23 April 2013
}

The past few decades have seen an explosion in studies exploring the effects of emotion on time judgments. The aim of this review is to describe the results of these studies and to look at how they try to explain the time distortions produced by emotion. We begin by examining the findings on time judgments in affective disorders, which allow us to make a clear distinction between the feelings of time distortion that originate from introspection onto subjective personal experience, and the effects of emotion on the basic mechanisms involved in time perception. We then report the results of behavioral studies that have tested the effects of emotions on time perceptions and the temporal processing of different emotional stimuli (e.g. facial expressions, affective pictures or sounds). Finally, we describe our own studies of the embodiment of timing. Overall, the different results on time and emotion suggest that temporal distortions are an indicator of how our brain and body adapt to the dynamic structure of our environment.

\section{Keywords}

Time, timing, emotion, embodiment, depression

\section{Introduction}

"It is through effort and desire that we got to know time.

We still have the habit of estimating time on the basis of our desires, our efforts, our own wills."

Jean-Marie Guyau (1890). La genèse de l'idée de temps.

Throughout the 20th century, researchers amassed data demonstrating that

* To whom correspondence should be addressed. E-mail: sylvie.droit-volet@univ-bpclermont.fr 
rations in the hundreds of milliseconds to minutes ranges, and that the variability (standard deviation) in their estimates, i.e. the sensitivity to time, increases linearly with the length of intervals to be timed (scalar property), consistently with the Weber's law. This led them to suggest that humans and animals share a primitive sense of time, with its hallmark characteristic: the scalar property. As a result, some researchers tried to develop and test models of the mechanism (i.e. an internal clock) that is putatively responsible for this accurate measurement of time, and to pinpoint its location in the brain (see other articles in this issue of Timing and Time Perception). Time has thus come to be regarded as a kind of objective dimension of the world that exists independently of us and which we can measure. However, in apparent contradiction with the idea of an internal mechanism to measure time, subjective time in humans seems to be 'elastic'. Humans often have the uncanny impression that time is speeding up, slowing down or even grinding to a halt. When individuals become depressed, for example, they experience a slowing down of time, such that 'a day feels like a year' (Ratcliffe, 2012). Similarly in everyday life, our experience of time fluctuates according to our affects. Time seems to drag by when we are waiting for our loved ones and to fly by once we have been reunited with them and are overwhelmed by happiness. Subjective time is thus highly dependent on both internal and external contexts. This is the paradox identified by Droit-Volet \& Gil (2009). Why are our time estimates so variable if we possess a sophisticated mechanism for measuring time? What self-respecting clockmaker would keep such a clock? Do the time distortions observed in humans cast doubt on the existence of a dedicated mechanism in our brains for measuring time? In other words, what do the time distortions caused by emotion tell us about time judgments?

The aim of this article is to review the results of behavioral studies that have investigated the effects of emotion on time judgments in humans. We begin by describing the findings on time judgments in affective disorders, which allow us to make a clear distinction between the feelings of time distortion that originate from explicit introspection onto subjective personal experience, and the effects of emotion on the basic mechanisms involved in time perception. We then report the results of studies exploring the effects of emotion states on time perceptions, and the temporal processing of different emotional stimuli (e.g. facial expressions, affective pictures or sounds). Finally, we present our own studies of the embodiment of timing. These highlight the function of temporal distortions, which appear to be a direct reflection of the way in which our brains and bodies adapt to the dynamic structure of our environment. 


\section{Subjective Experience of Time's Passage and Affective Disorders}

People often report that time seems to fly by when they are happy and drag by when they are sad. Time seems to stretch out or contract according to our mood. To account for these feelings, the phenomenologist Eugène Minkowski (1968/1988) distinguished between 'self-time' (Ich-Zeit) and 'world time' (Welt-Zeit) (Straus, 1947). As he explained, "self-time sometimes seems to go faster than world-time, giving the impression of fast-flowing time... By contrast, at other times, it seems to lag behind world-time, time drags on, we become morose and are overtaken by boredom" (p. 278). The contrast between these two kinds of time is particularly salient in the sad states experienced by patients suffering from depression (see DSM-IV; American Psychiatric Association, 1994). Depressed patients feel a kind of desynchronization between their own time and that of others (Fuchs, 2001). As one patient put it, 'world-time rushes past me' (Minkowski, 1968/1988). To investigate the explicit feeling of slowed-down time in depressive disorders compared to the world-time, several researchers have administered questionnaires to patients asking them whether time seems to go by at a different rate since the onset of their illness, whether it passes more slowly, more quickly or fluctuates from hour to hour, in comparison with normal experience (e.g. Bech, 1975; Blewett, 1992; Hoffer \& Osmond, 1962; Kitamura \& Kumar, 1982; Lehmann, 1967; Lewis, 1932; Mezey \& Cohen, 1961; Wyrick \& Wyrick, 1977). Depressed patients systematically report a slowing down of time. Depression is thus a mood disorder that changes the subjective experience of time (Gallagher, 2012; Msetfi, Murphy \& Kornbrot, 2012; Ratcliffe, 2012).

But which cognitive processes subtend this specific subjective experience of time, this feeling of a slowdown in the passage of time? In all probability, they have nothing to do with the basic mechanisms involved in time perception (for a recent review, see Droit-Volet, 2013a). To date, the results of studies of time perception in individuals with depressive symptoms have been inconsistent and contradictory, probably due to the heterogeneity of the populations sampled (clinically depressed patients vs. healthy participants with depressive symptoms) and the diversity of the temporal tasks employed (Msetfi et al., 2012). Some studies have failed to find any evidence of disturbed duration judgments for different levels of depression (Bech, 1975; Hawkins, French, Crawford \& Enzle, 1988; Kitamura \& Kumar, 1984; Mezey \& Cohen, 1961; Munzel, Gendner, Steinberg \& Raith, 1988; Prabhu, Agrawal \& Teja, 1969; Wyrick \& Wyrick, 1997). Other studies, by contrast, have found that depressive mood disrupts time judgments by causing time distortions and/or by reducing sensitivity to time (Bschor et al., 2004; Gil \& Droit-Volet, 2009; Grinker, Glucksman, Hirsch \& Viseltear, 1973; Kitamura \& Kumar, 1982; Kuhs, Hermann, Kammer \& Tolle, 1991; Msetfi et al., 2012; Mun- 
zel et al., 1988; Rammsayer, 1990; Sévigny, Everett \& Grondin, 2003; Tysk, 1984; Wyrick \& Wyrick, 1977). However, where time distortions have been observed, they have more often taken the form of temporal shortening, rather than the temporal lengthening described in depressive patients' statements (e.g. Bschor et al., 2004; Gil \& Droit-Volet, 2009; Grinker et al., 1973; Kuhs et al., 1991; Tysk, 1984). For instance, Grinker et al. (1973) found that depressed individuals underestimated time, and that this underestimation increased with the severity of their depression. In the same way, Tysk (1984) reported that severely depressed patients with melancholia or bipolar depression tended to underestimate short time intervals (7-27 s), while patients with manic disorders overestimated them and healthy patients provided accurate judgments. Regarding sensitivity to time, reduced sensitivity has been observed in students with depressive symptoms, but only for durations greater than 1 or 2 s (Msetfi et al., 2012; Sévigny et al., 2003). For shorter durations $(<1 \mathrm{~s})$, their sensitivity to time is similar to that of controls (Gil \& Droit-Volet, 2009; Msetfi et al., 2012; Sévigny et al., 2003). Nevertheless, for patients with major depression and melancholia, Rammsayer (1990) also found poorer time discrimination for very short durations in the milliseconds range. Researchers now acknowledge that the processing of long durations requires greater attention and working memory capacity, to keep track of the continuous flow of temporal information, than the processing of short durations (e.g., Coull, Vidal, Nazarian \& Macar, 2004; Lewis \& Miall, 2006). Consequently, depressive patients' deficits in the processing of suprasecond durations probably stem from their limited attentional resources or working memory capacity, rather than from a pure timing deficit, if such one exists. Individuals suffering from depression are known to have limited capacity in terms of vigilance, and sustained and selective attention (Gualtieri, Johnson \& Benedict, 2006), which necessarily has an impact on the processing of long durations. This can be attributed mainly to negative intrusive thoughts (i.e. ruminations), which reduce the amount of attention allocated to information processing by loading working memory (Koster, De Lissnyder, Derakshan \& De Raedt, 2011; Watkins \& Brown, 2002).

Rammsayer (1990) also suggested that the impaired timing in depressed patients results from a slowdown in the speed of their internal clock, associated with a general loss of energy and slowed motor and cognitive activity (Lemke, Koethe \& Schleidt, 2000). The slowing of the internal clock system could reflect a dysfunction in the dopaminergic activity of the frontostriatal loops subtending duration processing (see e.g. Harrington, Zimbelman, Hinton \& Rao, 2010; Matell \& Meck, 2000, 2004). Droit-Volet (2013b) recently showed that, in children, time resolution improves with information processing speed. However, as regards time distortions, it is theoretically difficult to demonstrate a clock-speed effect (shortening effect) on time perception when the speed of 
the clock remains the same throughout the experimental session. As there is a recalibration of the internal clock over time, stimulus durations are judged similarly whether the clock is running fast or slow. As numerous studies have demonstrated, the effects of clock speed acceleration or deceleration on time estimates are mainly observed in within-participants conditions, when different clock rates can be directly compared (e.g. Maricq, Roberts \& Church, 1981; Treisman, Faulkner, Naish \& Brogan, 1990; Wearden, Philpott \& Win, 1999). However, transient intrusions of ruminations ('I feel so lousy') in the course of an experimental session may bring about fleeting episodes of sadness in the depressed participants, triggering periods of internal clock slowing. When they administered a temporal bisection task, Gil \& Droit-Volet (2009) found a positive correlation between sad state, as assessed by the Brief Mood Introspection Scale (BMIS; Mayer \& Gaschke, 1988), and the magnitude of the subjective shortening effect. Furthermore, researchers have observed that tiredness increases faster over the course of an experimental session in participants with depression. Their level of arousal may also decrease across the experimental session, resulting in a relative slowdown in clock speed (for the effect of vigilance on time perception, see Wearden, 2008). Whatever the case, more research is required to improve our understanding of the effects of depressive symptoms on time judgments.

Nevertheless, the discrepancy between the findings on depressed patients' subjective experience of time and those on their performances on different time perception tasks suggests that these two forms of judgment involve different processes. Time perception involves mechanisms common to both human adults and other animals, as those described in the different models of the internal clock (see Gibbon, Church \& Meck, 1984; Matell \& Meck, 2000, 2004; Treisman, 1963). By contrast, the sense of time's passage probably results from human-specific introspection (i.e. the examination of one's conscious thoughts and feelings). In the case of depressive individuals, it may stem from an introspective awareness, based on personal subjective experiences, that something has gone wrong in their lives. They thus use time words, and the metaphor of time's passage, to express their boredom and their lack of interest and pleasure in everyday life. As Heidegger noted (1927/1995), when nothing significant happens to absorb our attention, we become increasingly aware of the passage of time. In conclusion, depressive patients' sense of time slowing down may derive from their introspection about life changes, and their awareness of their illness and its impact on their lives, rather than from changes in the mechanisms involved in time perception, although the latter cannot entirely be excluded. Consequently, not only does his feeling of time's passage refer to a time scale different from that of the perception of time, it also involves processes linked to memories and expectations that are not considered in models of time perception. It is therefore important to distinguish 
between the explicit awareness of time's passage and the direct perception of time. A disturbance in the former does not systematically imply a disturbance in the latter.

We recently designed a questionnaire to probe awareness of time distortions (Lamotte, Chakroun, Droit-Volet \& Izaute, submitted). In the first step of the development of our Metacognition Questionnaire on Time (MQT), we asked participants $(N=532)$ more than 100 questions about a wide range of factors liable to affect time perception, including coffee consumption, body temperature, attention, stress, and anger. Factorial analyses yielded a twofactor solution, with one factor relating to attention, and the other to emotion. People are therefore only aware of the effects of attention and emotion on the passage of time. In addition, as regards emotion, only sadness and happiness are judged to affect the sense of time's passage. As we will see below, however, research data on emotion and time perception show that other emotions, such as anger and fear, can also generate time distortions in temporal discrimination tasks. One plausible explanation for this is that the effects of certain emotions, such as fear and anger, on time perception are automatic and unconscious. In line with this idea, Gil, Niedenthal \& Droit-Volet (2007) found that when very young children (3 years old) devoid of reflexive thought on time's passage were shown angry faces, they displayed adult-like time distortions. Furthermore, although sadness is judged to modify the passage of time, no clear effect of sadness (induced by different technics) has ever been reported on time perception (Droit-Volet, Brunot \& Niedenthal, 2004; DroitVolet, Fayolle \& Gil, 2011; Droit-Volet \& Meck, 2007; Gil \& Droit-Volet, 2011a). In conclusion, these different results point to a clear distinction in humans between the awareness of the effects of emotion on the subjective experience of time (sense of time's passage) and the implicit effects of emotion on the perception of durations of a few hundred milliseconds or seconds. The effects of affective states on time judgments thus depend on the nature of the judgments that are elicited (i.e. declarative vs. implicit judgments) and the underlying mechanisms. In our laboratory, we recently tested the relationship between these two forms of time judgment by examining how awareness of time distortions affects time perception. We found that the more aware participants were of time distortions generated either by exposing them to emotion or by diverting their attention away from the temporal processing, the more accurate they were in their time judgments (Lamotte, Izaute \& Droit-Volet, 2012, in preparation). Awareness of time distortions may thus give us cognitive control over our automatic tendency to distort time in certain situations. In other words, we can overcome spontaneous emotion-related time distortions by force of mind. 


\section{Mood and Time Perception}

It is important to make the distinction between mood and emotion (e.g. Damasio, 1999; Ekman \& Davidson, 1994; Frijda, 2000). Contrary to emotion, which corresponds to transient affective reactions to specific emotional situations, mood can last for several minutes, hours, or even days. It is also less intense and more diffuse than emotion. Emotion is therefore transient, while mood is longer lasting. Mood fundamentally colors every aspect of our lives. For instance, in the case of an individual who has secretly been in love with someone for several months, this love will have brought about positive and lasting changes in his or her mood, but will also trigger brief and sudden emotions (reflected in blushing and stuttering) whenever that individual comes face to face with the object of his or her desire. The durability of affective states is thus one of the major differences between emotion and mood.

Regarding durable affective states, to date, there is no clear evidence of their disruptive effects on time perception per se, independently of attentionrelated effects. As explained above, individuals who experience a deep change in their mood, as in the case of depression, or who exhibit specific mood traits, such as anxiety or phobias, do not display any major distortion in their ability to perceive time, although their sensitivity to time appears to be reduced for long durations (Msetfi et al., 2012; Sévigny et al., 2003). As explained before, this may be due to the fact that significant variations in time judgments emerge with contrast effects (transient slowing down or speeding up of clock speed), but not with a consistently slow clock. Nevertheless, some recent studies have suggested that mood modulates the magnitude of the transient effects of emotional stimuli on time perception, by modifying the processing of emotional stimuli. In other words, mood affects time judgments by interacting with the effects of emotion. For example, Tipples (2008) found that the duration of negative-valence facial expressions (angry/fearful faces) was overestimated, compared with that of neutral expressions, and that this temporal overestimation increased with individual negative emotionality, as assessed by the Emotionality-Activity-Sociability (EAS) Temperament Survey for adults. More recently, Tipples (2011) established a significant correlation between the magnitude of temporal overestimations for angry faces and inter-individual levels of fearfulness, distress and trait anxiety, with regression analyses revealing that fearfulness was the best predictor of time distortions for angry expressions. Along the same lines, Bar-Haim, Kerem, Lamy \& Zakay (2010) showed that individuals reproduce longer durations for fearful expressions than for neutral ones, especially when they have high levels of anxiety. Buetti \& Lleras (2012) also showed that phobia modulates the magnitude of time distortions when individuals are shown pictures of their phobic object: the greater their fear of spiders, the more participants overestimated the duration of spider 
pictures. In sum, these different results support the so-called mood-facilitation hypothesis, or mood-congruency hypothesis, whereby the processing of emotional events is biased by the person's mood. For example, a negative mood introduces a negative bias into the processing of emotional stimuli. Consistent with the notion of fear-specific system activation (Öhman \& Mineka, 2001), people who feel and experience the emotion of fear on a daily basis are more reactive to threatening stimuli, which, in turn, can amplify their time distortion in the presence of these stimuli. However, as stated by Tipples himself, further studies are needed to understand the mechanisms behind these mood-driven variations in emotion-related time distortions (e.g. attention biases, top-down regulation of emotion).

As far as healthy people without specific mood disorders are concerned, our team recently ran an experiment testing the impact of a change in mood on temporal discrimination (Droit-Volet et al., 2011). To induce this mood change, we used a technique based on the presentation of long emotional video clips $(2 \times 10 \mathrm{~min})$ (from Schaefer, Nils, Sanchez \& Philippot, 2010). More specifically, we looked at the participants' ability to discriminate between different durations of a nonaffective stimulus (blue circle) in a temporal bisection task before and after mood induction, as assessed by the BMIS. Results showed that the participants perceived the neutral stimulus as lasting longer after they had viewed threatening films (e.g. Shining) than before (Fig. 1). As expected, the neutral film did not produce any time distortions. We interpreted the lengthening effect of viewing threatening films as resulting from arousaldriven mechanisms, consistent with the subjective levels of arousal reported in the BMIS. According to the principle of internal clock models based on the scalar expectancy theory (Gibbon, 1977; Gibbon et al., 1984), the representation of time is derived from the accumulation of temporal units emitted in the brain by an internal clock-like system. Consequently, when the level of arousal increases and speeds up the internal clock, more temporal units are accumulated, and the stimulus duration is judged to be longer (for further discussion of the models of timing and its neural location, see e.g. Coull, Cheng \& Meck, 2011; Ivry \& Schlerf, 2008; Mauk \& Buonomano, 2004; Wiener, Turkeltaub \& Coslette, 2010).

Moreover, whereas participants reported feeling sadder and being less aroused after viewing the sad films (e.g. Philadelphia), we failed to observe any related time distortions. The mood change induced by the sad films in our experiment was, perhaps, not sufficiently strong to affect time discrimination. Nevertheless, we might have expected the significant loss of vital energy brought about by the experience of sadness in our study, as attested to by the BMIS scores, to slow the internal clock down and produce a temporal shortening effect. This raises new questions about the function of time distortions, i.e. the usefulness or otherwise, in terms of behavioral adaptation, of the time dis- 

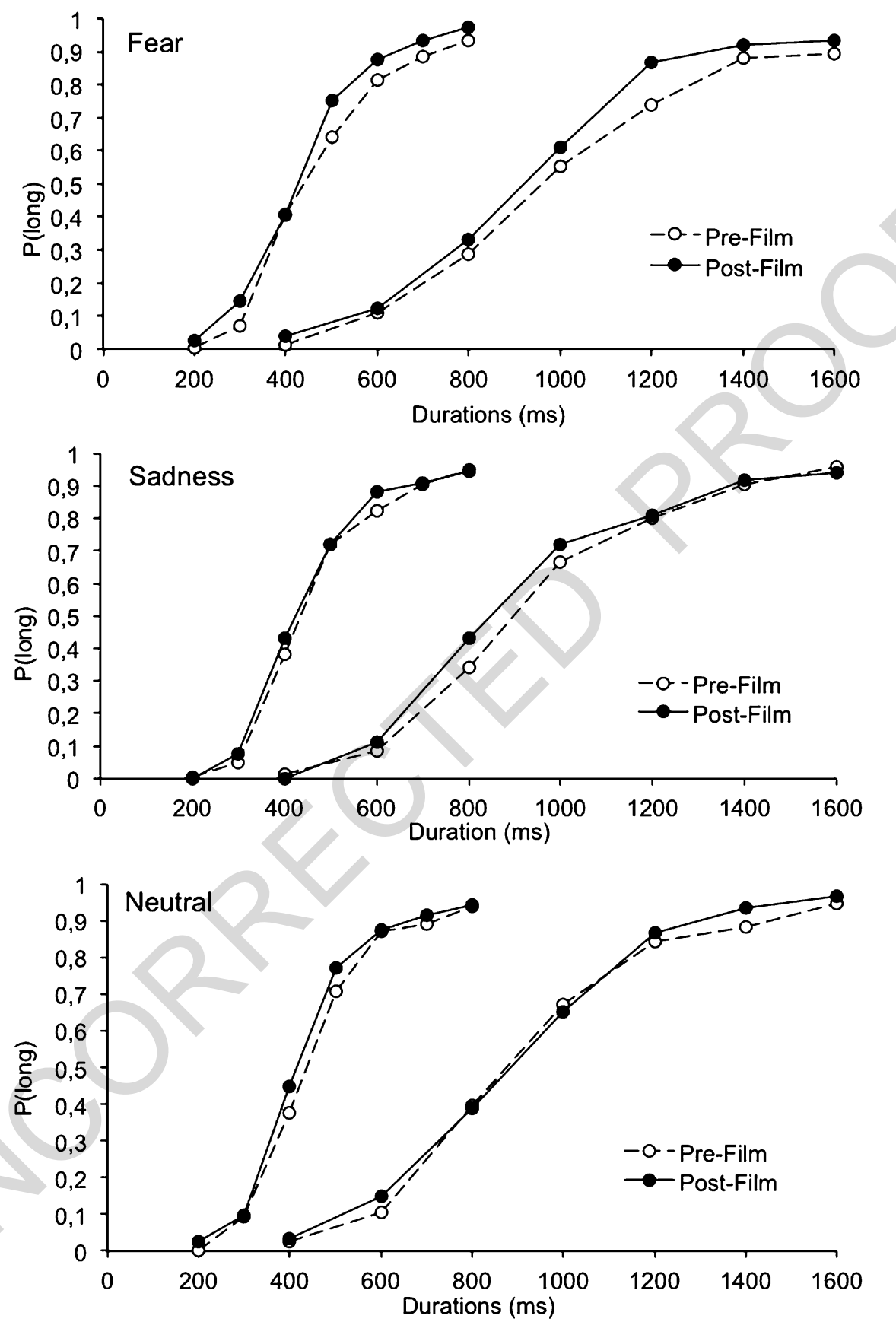

Figure 1. Psychometric function for fear, sadness and neutral. Proportion of long responses plotted against comparison durations (ms) for the bisection task before and after viewing the emotional or the neutral films in the $200 / 400$ and the $800 / 1600$-ms duration range. 
tortions in everyday life. In other words, why, and by which mechanisms, does our brain produce time distortions? As we will see below, when emotional stimuli induce negative, high-arousal emotion known to trigger the defense mechanisms for survival shared by humans and other animals, the findings on the effects of emotion on time perception are clear and consistent. However, when emotional stimuli are more complex and low arousing, the findings are more inconsistent, depending on the salience and relevance of the emotional stimuli in the specific context.

\section{The Effect of Negative, High-Arousal Emotion on Time Perception}

Researchers wishing to examine the impact of emotional stimulus processing on time perception can choose from a wide range of validated material, including emotional faces, such as the Pictures of Facial Affect (POFA; Ekman \& Friesen, 1976), the pictures of various emotional scenes contained in the International Affective Pictures System (IAPS; Lang, Bradley \& Cuthbert, 1999), the emotional sounds in the International Affective Digitized Sounds system (IADS; Bradley \& Lang, 1999), and music (e.g. Peretz, Gagnon \& Bouchard, 1998). The choice of material is critical, as the relationship between emotional stimuli and time judgments is driven by different emotion parameters. The clearest findings to date have come from studies using emotional stimuli that are both highly negative and highly arousing, such as faces expressing anger (e.g. Bar-Haim et al., 2010; Doi \& Shinohara, 2009; Droit-Volet et al., 2004; Gil et al., 2007; Tipples, 2008), and emotionally charged pictures evoking either danger (e.g. a snake) or very uncomfortable events (e.g. mutilated bodies) (e.g. Angrelli, Cherubini, Pavese \& Manfredini, 1997; Gil \& DroitVolet, 2012; Grommet et al., 2010; Lambrechts, Mella, Pouthas \& Noulhiane, 2011; Yamada \& Kawabe, 2011), or very unpleasant sounds (Mella, Conty \& Pouthas, 2010; Noulhiane, Mella, Samson, Ragot \& Pouthas, 2007). In these different studies, negative, high-arousal stimuli were systematically judged to last longer than neutral stimuli, whereas the sensitivy to time did not change. These results replicate findings of a series of studies on the temporal estimation of a specific, non-standardized, stressful event, such as a stressful film of a given duration (e.g. $3 \mathrm{~min}$ ) (the September 11 terrorist attack, bank robbery) (Anderson, Reis-Costa \& Misanin, 2007; Loftus, Shooler, Boone \& Kline, 1987), the time period (45 s) spent watching a live spider for arachnophobic and non-arachnophic participants (Watts \& Sharrock, 1984), the first jump of novice skydivers (Campbell \& Bryant, 2007) or the moving of participants on a treadmill going toward or away a precipe (Langer, Wapner \& Werner, 1961). For a last example, Stetson, Fiesta \& Eagleman (2007) showed in their study that the participants overestimated the duration of a freefall from a tower $(2.49 \mathrm{~s})$, consistently with their verbal report that their fall 'had seemed to take 
a very long time', whereas their temporal resolution (temporal thresholds of the discrimination between 2 digits) has not changed with stress, that is, has not been improved or deteriorated.

This lengthening effect is also entirely consistent with findings on fear conditioning in animals (e.g. Brown, Richer \& Doyère, 2007; Meck, 1983) and human adults using electric shocks or aversive sounds (Droit-Volet, Mermillod, Cocenas \& Gil, 2010a; Falk \& Bindra, 1954; Hare, 1963). For example, Droit-Volet et al. (2010a) showed that the expectation of a fearful sound (50-ms burst of 95-dB white noise) that hurts the ears and produces a defensive startle reflex shifts the psychophysical function toward the left in a temporal bisection task, compared with that of a non-aversive sound (50-ms beep), or no sound, consistent with a fear-related temporal lengthening effect (Fig. 2). The point of subjective equality (PSE), or bisection point (BP) (i.e. proportion of stimulus durations judged to be long $=0.50$ ), was thus significantly lower in the fearful condition than in the non-fearful ones. In addition, their results showed that the sensitivity to time was not affected in the case of fear-related time distortion, and that the scalar properties of time perception hold: (1) the discrimination of the different duration values remained good, and (2) the variability in temporal discrimination always increased with the temporal values, the Weber Ratio (a sort of coefficient of variation) remaining constant for the different duration ranges. In sum, a forthcoming threatening event produces a

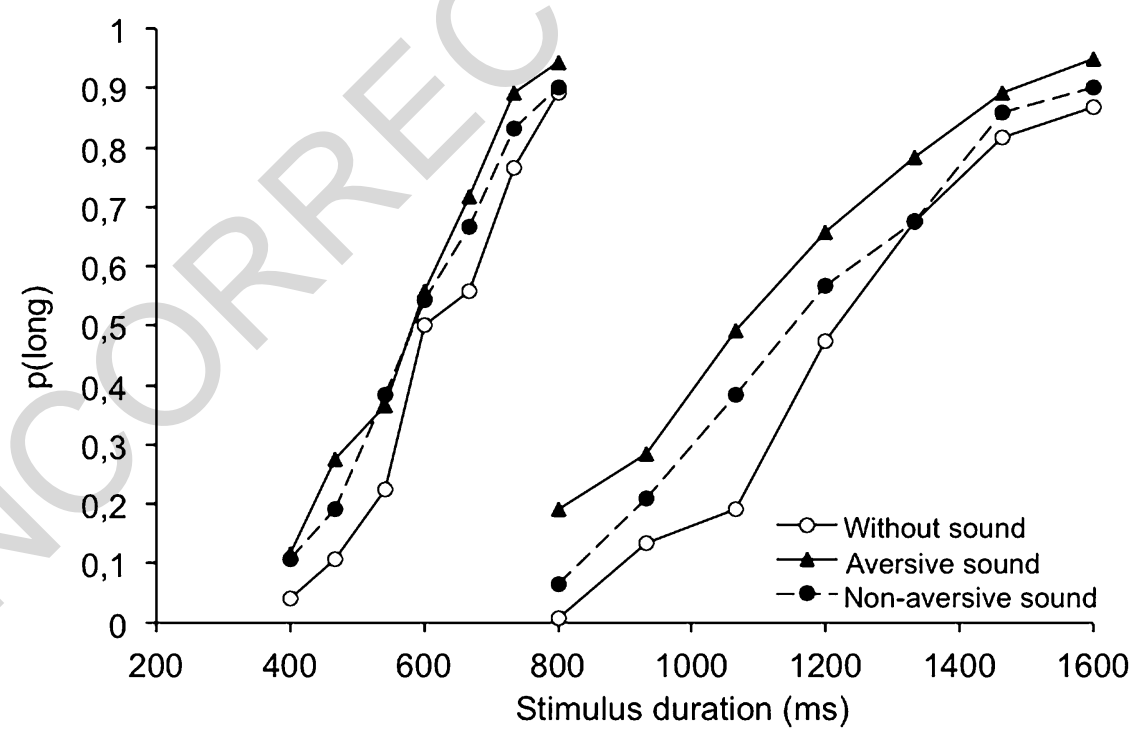

Figure 2. Proportion of long responses plotted against comparison durations (ms) for the tri- 
time distortion, with time being judged longer than normal, but without disrupting sensitivity to time. This demonstrates that the emotion of fear does not disorganize the perception of time. On the contrary, as argued by Droit-Volet $\&$ Meck (2007), this time distortion enables the organism to adapt efficiently to forthcoming events (imminent danger), by ensuring that it is prepared to act earlier.

Until now, there has been no clear consensus on the mechanisms underlying the lengthening effects produced by emotion. However, in the case of negative, high-arousal emotional stimuli (the sight of a snake or the angry face of a conspecific), that have an innate propensity to trigger defense reactions for survival (Öhman \& Soares, 1998), most researchers agree that this temporal lengthening effect results from an acceleration of the internal clock rate, associated with an increase in arousal level. Whenever a threat presents itself, the body indeed activates a stress response, a state of alarm, that triggers an array of changes in the autonomic (increase in respiratory, heart rate) and somatic (facial and bodily motor expression) nervous systems designed to prepare the organism to act as fast as possible (fight or flight). We can logically assume that it also speeds up the internal clock system involved in time perception. According to the mathematical predictions of scalar expectancy theory, the clock-speed hypothesis would be confirmed by a slope (multiplicative) effect on temporal psychophysical functions with greater temporal overestimation for long stimulus durations than for short ones (for further discussion, see Droit-Volet \& Meck, 2007). Evidence was found in pharmacological studies showing that the administration of drugs (e.g. methamphetamine) that increase the level of dopamine in the brain lengthens subjective time consistently with a multiplicative effect, as though the rate of the internal clock had increased (e.g. Buhusi \& Meck, 2002; Maricq et al., 1981; Meck, 1983; Rammsayer, 1993; Rammsayer \& Vogel, 1992; Williamson, Cheng, Etchegaray \& Meck, 2008). Numerous studies on time perception in threatening conditions have indeed reported a slope effect for time estimates, thus supporting the clock-speed hypothesis. In Fig. 2, for example, the magnitude of the difference in the proportion of long responses between the aversive and non-aversive conditions is greater for the long duration range (800-1600) than for the short one (400800) (Droit-Volet et al., 2010a). This clock-speed hypothesis is also supported in several studies by other indicators evidencing changes in arousal level, such as self-reports in questionnaires assessing subjective levels of arousal, or physiological measures like changes in heart rate or skin conductance (Angrilli et al., 1997; Droit-Volet et al., 2010a; Mella et al., 2010).

However, when participants are required to judge the presentation duration of negative pictures taken from the IAPS, this slope effect is not always observed. Grommet et al. (2010) have for example found an intercept (additive) effect rather than a slope effect. In scalar expectancy theory, this intercept 
effect is linked to attention mechanisms. According to the attention models of the internal clock (Burle \& Casini, 2001; Lejeune, 1998; Zakay \& Block, 1996), an attentional switch, connecting the pacemaker to the accumulator, closes at the beginning of each stimulus to be timed, thereby letting the pulses entering into the accumulator. Earlier closure of the attentional switch therefore increases the number of pulses included at the beginning of the stimulus duration, but this addition number of pulses staying the same (additive effect) whatever the total duration. Consequently, some researchers have surmised that attention processes contribute to the effects of negative, high-arousal emotion on time judgments, as threatening signals attract attention more quickly (Lui, Penney \& Schirmer, 2011). For example, Lui et al. (2011) showed that when individuals were shown an emotional picture from the IAPS just before the comparison duration, it captured their attention to the detriment of the timing of the subsequent signal.

The problem is that threatening signals are assumed to both attract attention (faster orienting attention), and modulate the organism's arousal level. Consequently, we can assume that arousal mechanisms play a crucial role, but are also preceded and/or followed by other attention-related mechanisms (e.g. oriented attention, inhibition) that have the power to boost or erase the arousal effects. One strong argument in favor of arousal's critical role is that its effect on timing is short-lived, that is, it rapidly returns to its baseline state (Bar-Haim et al., 2010). In other words, it quickly melts away in the course of temporal processing. By contrast, as we have seen, the attention effect (earlier switch closure) is assumed to prevail for different duration values, even long ones. Consequently, we would expect to observe an effect of arousal on the timing for short stimulus durations, but scarcely if at all for longer ones. Consistent with this prediction, Bar-Haim et al. (2010) obtained an overestimation of fearful faces for a short, 2-s duration, but not for longer, 4- or 8-s durations. Similarly, Angrilli et al. (1997) reported temporal overestimation for emotional pictures displayed for $2 \mathrm{~s}$, and temporal underestimation for pictures with a longer duration (i.e. 6 s). Recently, examining the cross-modal link between visual and tactile perception in bisection, Shi, Jia \& Müller (2012) also found a lengthening effect on time estimates in the tactile modality, after participants had viewed threatening pictures, but only in the 300-900-ms duration range, not the 1000-1900-ms one. Moreover, using IAPS pictures, Gil \& Droit-Volet (2012) found lengthening effects both for short (200-800 ms) and longer durations (400-1600 ms), but which were more consistent with a slope effect for the former and an intercept effect for the latter.

Overall, these results demonstrating a short-lived effect of the processing of emotional stimuli on the judgment of their duration point to the involvement of an automatic, arousal-based mechanism that speeds up the internal clock system in the brain. However, they also suggest that there is a cascade 
of different mechanisms that operate simultaneously or not during temporal processing, depending on the dynamics of the emotion processing over time. For example, Smith, McIver, Di Nella \& Crease (2011) obtained a shortening effect in a temporal bisection task for IAPS pictures with very short durations of 100-300 ms, while they replicated the lengthening effect for longer durations of $800-1600 \mathrm{~ms}$. They thus ascribed this shortening effect to the rapid activation of the amygdala during the initial perceptual stage (within the first $300 \mathrm{~ms}$ ), before the influence of other brain structures connected with the amygdala. The amygdala's role in the rapid detection of threatening signals is well known (Ledoux, 2000, 2007; Phelps \& Ledoux, 2005). Meck \& MacDonald (2007) revealed the function of the amygdala in selective attention to temporal information in an emotional context. Indeed, they showed that when rats had to simultaneously time a 50-ms visual stimulus and a $10-\mathrm{ms}$ auditory stimulus paired with a foot shock, they were unable to divide their attention and time both signals simultaneously. By contrast, when lesions in the amygdala blocked this fear-related impairment, they were able to time the signals simultaneously. However, the amygdala sends projections to many cortical and subcortical regions capable of influencing perception and behavior in multiple ways. The detection of a threatening signal can thus also trigger a series of arousal-based processes in the organism involved in action motivation for survival, which include the speeding up of the internal clock. It is now widely accepted that fear is highly dependent on the dopaminergic (DA) system (Phelps \& Ledoux, 2005). Within the framework of the Striatal Beat Frequency (SBF) model (Mattel \& Meck, 2000, 2004), Meck, Penney $\&$ Pouthas (2008) reported two types of DA release: a phasic and tonic DA release. The role of the phasic DA release would be to serve as a start gun by indicating the onset of a relevant signal for the synchronization of the cortical oscillations and the resetting of the membrane properties of the striatal spiny neurons. By contrast, the role of the tonic DA release is to modulate the frequency of the cortical oscillation, that is, the speed of the internal clock system. However, in behavioral studies, given that attention and arousal are distinct but interrelated processes, they are actually quite hard to untangle (Paus, 2000; Robertson \& Garavan, 2004; Vuilleumier, 2005). As Vuilleumier (2005) explains, in emotionally significant situations, the increase in vigilance is correlated with an increase in arousal. Furthermore, higher-order cognitive processes (prolonged holding attention, inhibition) may take place after the first automatic steps of emotional stimulus processing, related, for example, to the appraisal of emotional stimuli or the self-analysis of felt emotion. And these controlled cognitive processes can modify the output of time judgments. However, the dearth of studies on the effects of emotion on the estimation of long durations prevents us from examining this hypothesis. In sum, the major difficulty in investigating the mechanisms underlying the influence of emotion 
on time judgments stems from the fact that emotion is a dynamic process that changes over time, as do its effects on temporal processing. In addition, Gil \& Droit-Volet (2011b) recently showed that the effects of emotion on time judgments (i.e. lengthening effect) do not emerge in every type of temporal task, despite the use of the same emotional stimulus (angry face). Taken together, these different findings indicate that the effects of emotion on time judgments are highly context-dependent, relying on the nature of the temporal judgments required, the nature of the emotional stimuli used, and their motivational relevance to individuals.

\section{The Time Judgment of Emotional Stimuli: the Critical Role of Their Motivational Relevance}

When we do not use clear, negative, high-arousal emotional stimuli, or a fear-conditioning situation, gauging the impact of emotion on time perception becomes highly complex, as time judgments are influenced by numerous factors. This is particularly true for studies which, instead of examining the impact of emotional state on time judgments for neutral stimuli, explore the judgments of emotional stimulus durations. Here, the challenge is to identify the source of the time distortions (emotion and/or stimulus features), given that the effects of the physical features of the emotional stimuli (e.g. color, complexity) can potentially interfere with the effects of the emotion per se. To be emotionally charged, emotional stimuli must have certain perceptual features. Negative emotional pictures, for example, are more complex than neutral pictures, with more reds and dark colors. Sound characteristics also vary according to the type of emotion being induced. For example, a sound inducing fear has a faster tempo than a sound inducing sadness. In the horror film Jaws, Steven Spielberg increased the tempo of the soundtrack to emphasize the protagonists' fear of the approaching shark. Droit-Volet et al. (2010a) recently showed that differently valenced pieces of music (sad vs. joyful) produce the same underestimation of time when they are matched on tempo. Moreover, unpublished findings obtained in our laboratory reveal that emotional music and a simple auditory stimulus composed of clicks produce the same time distortion in bisection when they are matched on tempo (Droit-Volet, Ramos, Bueno \& Bigand, in preparation). The problem is that changes in tempo affect our perception of time, independently of the emotion being induced (e.g. Droit-Volet \& Wearden, 2002; Treisman et al., 1990; Wearden et al., 1999). For emotional sounds, tempo and induced emotion are thus confounded variables, and their respective roles on time judgments are difficult to untangle.

Consequently, when investigating the processing of emotional stimuli, it is important to methodologically clarify the effect of their physical features on time judgment, as well as their relevance for the participants, as this can trig- 
ger different adaptative responses from the organism (for a recent discussion, see Ledoux, 2012). For example, emotional facial expressions provide cues for social interactions. They give social information to the perceiver, who then reacts according to his/her understanding of the received message (Fridlund, 1997). Within this framework, our studies have allowed us to show that the perception of an angry/fearful face, a sad face or a happy face results in time being perceived as lasting longer, compared with neutral faces (Droit-Volet et al., 2004; Droit-Volet \& Meck, 2007; Gil \& Droit-Volet, 2011a). However, the degree of temporal lengthening varies as a function of the facial expression, being greater for anger/fear than for happiness/sadness, and greater for happiness than for sadness. These results can be explained by different arousal effects linked to differences in the motivation to act (e.g. approach motivation) (Fridja, 2007), and more specifically in the urgency of action readiness in the presence of each type of emotional face: to fight an aggressive person, to flee a potential danger reflected in a fearful individual, to affiliate with a pleasant person and to offer assistance to a sad person. By contrast, faces expressing disgust do not produce any time distortion (Droit-Volet \& Meck, 2007; Gil \& Droit-Volet, 2011a). This is probably due to the lack of relevance, in terms of action motivation (approach/avoidance), for an individual who sees another person expressing disgust. Here, the most important thing for the perceiver is to analyze the source of that disgust (poor food quality), in order to avoid eating bad food for health. Nevertheless, findings for the same disgust emotion differ when emotional stimuli other than facial expressions are used (see Fig. 3 for a sample of the stimuli used in our studies). For example, when we used high-disgust scenes (e.g., a mutilated head) taken from the IAPS, we obtained an overestimation of time for the disgust emotion compared with a neutral emotion (Gil \& Droit-Volet, 2012). In addition, the temporal overestimation was greater for the disgusting scenes than for the frightening scenes, even though they were matched on arousal level. In contrary, when the pictures used to induce disgust featured disgusting food, we obtained not an overestimation, but an underestimation, compared with neutral pictures (Gil, Rousset

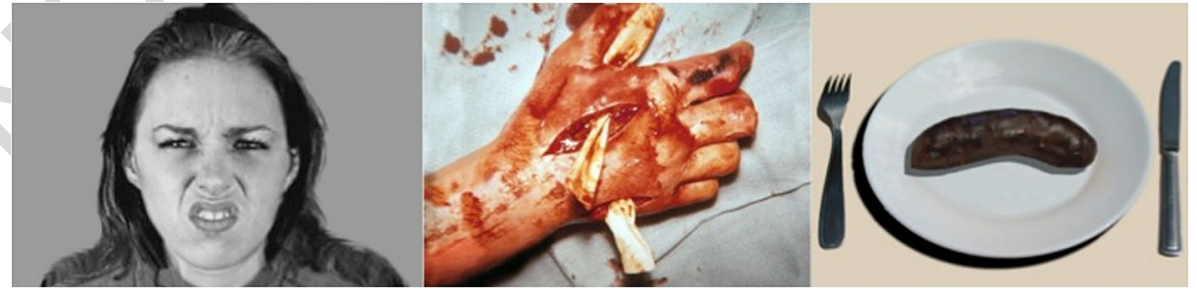

Figure 3. Different emotional stimuli used for the same emotion of disgust: (left) face expressing disgust, (middle) disgust scene from the IAPS (picture no. 9405), (right) disgusting food. This figure is published in color in the online version. 
\& Droit-Volet, 2009). The fact that the same evoked emotion (e.g. disgust) can have varying effects on time judgments, according to the type of stimulus (Fig. 3), suggests that the function/meaning of the emotional stimulus plays a critical role, triggering different reactions from the organism and activating different areas in the brain. Consistent with this hypothesis, Gil \& Droit-Volet (2011c) found that young children undergo time distortions just as adults do, when shown facial expressions (shame), but only once they are able to understand the message conveyed by the faces. In another study, Doi \& Shinohara (2009) observed that the duration of angry faces was judged to be longer than that of neutral faces, especially when the angry faces had a straight gaze rather than an averted one. By contrast, gaze direction had no effect on temporal estimations for happy faces. The effects of angry faces on time perception therefore depend on the meaningfulness of the emotion being expressed for the other person: An angry face with an averted gaze is not a direct threat for the perceiver of that expression. The results of recent experiments conducted by Gable \& Poole (2012) also suggest that the effects of positive pictures on judgments of their duration are mediated by the underlying approach motivation. To be able to answer questions about the mechanisms behind the effects of emotion on time judgments, we therefore need to identify the relevance of the emotional stimuli and the individual motivation underlying time distortions (e.g. movement, action). As regards the embodiment of other people's timing, the subject of the following section, time distortions can reflect our ability to adapt to another person's timing and the dynamics of our social environment.

\section{Embodiment of Timing}

Time is an integral part of our daily lives, regardless of whether we are in a hurry, relaxed, gripped by an emotion or bored stiff. The idea is that each and every event and action, or elapsed time between two events, is automatically encoded and stored in memory together with its intrinsic dynamical property (duration), relative to its initial internal or/and external encoding context (see Balsam, Drew \& Gallistel, 2010). According to the theory of grounded time (for a further presentation see Droit-Volet, in press since 2010), directly derived from the theories of grounded cognition, sometimes also called embodied cognition (Barsalou, 1999, 2008; Niedenthal, 2007), some temporal judgments are based on changes in emotional and sensory-motor states, in bodily states, that are experienced and/or re-experienced/reactivated during the judgment process (Chambon, Droit-Volet \& Niedenthal, 2008; Chambon, Gil, Niedenthal \& Droit-Volet, 2005; Droit-Volet \& Gil, 2009; Effron, Niedenthal, Gil \& Droit-Volet, 2006). This is clearly illustrated in the primitive temporal judgments of preschool children, who are not yet able to conceptualize time as a continuous and uniform dimension allowing them to measure all events 
independently of their characteristics (see Droit-Volet, 2011). For example, before the age of 6 years, young children do not understand that the duration learned for one particular action can be transferred to another new action (Droit-Volet \& Rattat, 1999; Rattat \& Droit-Volet, 2002). For them, time is 'multiple'. In other words, there is a plurality of times, a plurality of durations, each associated with a specific event or action they experienced in the past. Their explicit judgments of time are therefore intrinsically rooted in the characteristics of previously experienced actions or events. For instance, actions that require particular effort are judged by young children to be longer (Droit-Volet, 1998; Piaget, 1946). Similarly, a light or a movement is judged to be longer when the brightness of the light or the speed of the movement increases (e.g. Levin, 1979; Piaget, 1946; Zuili \& Fraisse, 1946). This does not mean that young children are unable to estimate time accurately. However, for this accurate measurement to take place, they must either repeatedly experience the same duration for different samples of the same event (i.e. representation in the form of a distribution of durations with a mean equal to $t$ ), or else implicitly judge time in neutral experimental conditions controlled in a laboratory. In sum, primitive subjective estimations of time in young children are grounded in their emotional and sensory-motor experiences and their intrinsic dynamical properties.

The experience or the reactivation in memory of the dynamic of a previous action or event may therefore influence a current time judgment. In a recent study, Nather, Bueno, Bigand \& Droit-Volet (2011) administered a time bisection task in which participants were shown pictures of Edgar Degas' sculptures representing a ballerina performing different ballet steps. Participants judged the durations to be longer when the ballerina was in an arabesque position rather than in a rest position, even though the pictures were all displayed for exactly the same length of time. Within the theoretical framework of grounded time, the authors assumed that this lengthening effect resulted from the reactivation in memory of movements associated with the body postures featured in the pictures, with an acceleration of the internal clock during the internal simulation of the arabesque movement. This is consistent with the work on mirror neurons demonstrating that the motor brain areas underlying the execution of a particular action are activated when we watch another person perform that action (Gallese, Fadiga, Fogassi \& Rizzolatti, 1996; Rizzolatti, Fadiga, Gallese \& Fogassi, 1996). In the same line, Pulvermüler (2005) showed that simply reading an action word activates different regions of the reader's motor system, depending on which body parts are involved. A verb referring to an arm or leg movement therefore produces an arm or leg simulation in the corresponding area of the motor system.

However, Nather et al. (2011) only observed this body posture effect in time bisection for short durations (0.4-1.6 s), but not for longer ones (2-8 s). It is 
possible that the clock-speed effect triggered by the simulation of movement is 1 only fleeting, and rapidly disappears over the course of long duration processing (van Heijnsbergen, Meeren, Grèzes \& de Gelder, 2007). For this reason, we decided to replicate these time bisection results with other postures, and for two short duration ranges: one with short and long anchor durations of 100 and $400 \mathrm{~ms}$ (comparison durations: 100, 150, 200, 250 300, 350, $400 \mathrm{~ms}$ ), the other with short and long anchor durations of 200 and $800 \mathrm{~ms}$ (comparison durations: 200, 300, 400, 500, 600, 700, $800 \mathrm{~ms}$ ). For each duration range, we tested a group of 20 undergraduates from Blaise Pascal University (Clermont-Ferrand, France). For each bisection task, the participants were shown static pictures of three body postures suggesting different dynamic movements (Fig. 4): standing, walking, and running. Figure 4 shows the time bisection results for these three postures. There was a clear leftward shift of the

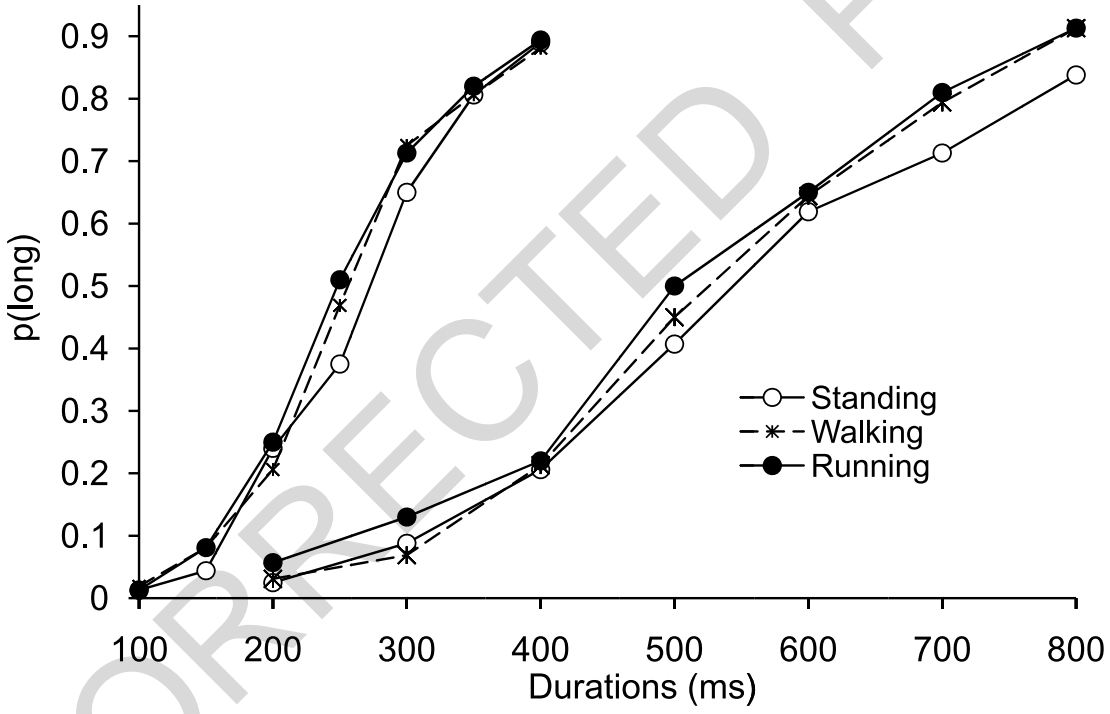

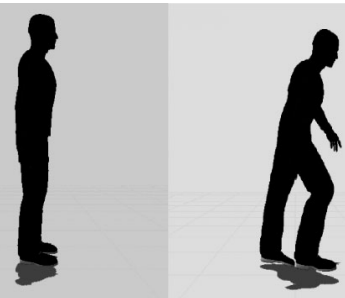

(1)
(2)

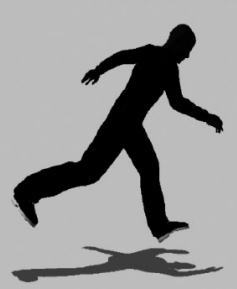

(3)
Figure 4. Proportion of long responses plotted against comparison durations (ms) for the pictures of 3 body postures depicting a man who is (1) standing up, (2) walking and (3) running in the $100 / 400$-ms and the 200/800-ms duration range. 
Table 1.

Mean and standard deviation of Bisection Points and Weber Ratios for the pictures of 3 body postures depicting a man who is (1) standing up, (2) walking and (3) running in two temporal bisection tasks, one with the short and the long anchor duration of 100 and $400 \mathrm{~ms}$, and the other with the short and the long anchor duration of 200 and $800 \mathrm{~ms}$

\begin{tabular}{|c|c|c|c|c|c|c|c|c|}
\hline & \multicolumn{4}{|c|}{ Bisection point } & \multicolumn{4}{|c|}{ Weber ratio } \\
\hline & \multicolumn{2}{|c|}{$100 / 400$} & \multicolumn{2}{|c|}{$200 / 800$} & \multicolumn{2}{|c|}{$100 / 400$} & \multicolumn{2}{|c|}{$200 / 800$} \\
\hline & M & $S D$ & M & $S D$ & M & $S D$ & M & $S D$ \\
\hline Standing & 283 & 57 & 579 & 108 & 0.26 & 0.07 & 0.29 & 0.08 \\
\hline Walking & 267 & 40 & 542 & 81 & 0.27 & 0.07 & 0.27 & 0.07 \\
\hline Running & 260 & 31 & 532 & 98 & 0.27 & 0.09 & 0.29 & 0.09 \\
\hline
\end{tabular}

psychophysical function for the picture of the running man compared with that of the standing man, the psychophysical function for the walking man being midway between the two. An ANOVA on the BP confirmed these results, indicating a significant main effect of body posture, $F(2,76)=5.71, p=0.005$, and a significant effect of duration range, $F(1,38)=187.44, p=0.001$, but no Duration range $\times$ Body posture interaction, $F(2,76)=0.82, p=0.44$ (Table 1). No significant effect was observed for the Weber ratio, either for duration range or for body posture (all $p \mathrm{~s}>0.05$ ). The BP value was therefore lower for the picture of the running man than it was for the picture of the standing man (396 vs. $430, t(39)=2.44, p=0.02)$, while the difference in BP values between the running and walking pictures failed to reach significance ( 396 vs. $405, t(39)=1.05, p=0.30$ ). These results therefore replicated the lengthening effect observed by Nather et al. (2011) and suggest that picture duration judgments were influenced by the reactivation in memory of action dynamics associated with the content of each picture. This finding is consistent with the results of studies showing that the perception of a movement produces time dilations. For instance, Wittmann, van Wassenhove, Craig \& Paulus (2010a) showed that an object moving towards an observer was perceived as longer in duration than the same object that was static or moving away. Wang \& Yi Jiang (2012) also observed a subjective temporal dilation in a bisection task when participants were presented with a motion sequence of point-light walker compared to a non-biological motion or a static picture with the same amount of point lights.

However, further investigations are also needed to understand the influence of the temporal memories activated during time judgments for body posture pictures. Several questions need to be answered. Do participants reactivate/simulate the action in their reference memory, together with its temporal properties, such the current time judgment directly derived from the timing of 
action simulated in memory. Do they reactivate other properties of this action (e.g. more movements, faster motion) that bias their time judgment, or do they simply develop an explicit feeling associated with a previously experienced action that also biases their judgment? In a functional magnetic resonance imaging (fMRI) study, Wittmann, Simmons, Aron \& Paulus (2010b) detected insular cortex activation during the duration ( 9 and $18 \mathrm{~s}$ ) encoding phase of a temporal reproduction task. The insular cortex is believed to be involved in the awareness of emotional and bodily states. Craig (2009) has therefore suggested that our awareness of time is based on our awareness of our bodily states. However, if this is the case, what roles do awareness of bodily states and the reenactment of action and its temporal properties play in time judgment?

Whatever the answers are to these questions, the embodiment of the timing of actions perceived in other people can be regarded as playing a fundamental role in everyday life, notably in social interaction. Embodying another person's time is important if we are to attune ourselves to it, in other words, if we are to predict the other person's behaviors and respond to them at the appropriate time. In their social interactions, mothers and children try to match their time, with the mothers slowing down their rhythm, speaking or walking more slowly, and the children trying to speed up. Conway (2004) showed that people share a more similar sense of time's passage when they interact than when they do not. When an adult is too slow, compared with the other members of the group (slower speech, slower learning), this shared sense may be disrupted, thus becoming a source of social exclusion. Conway (2004) argued that it is because individuals tend to become synchronized as a result of mutual influence that they have similar experiences of the passage of time. In this line, in one of our studies, we showed that empathic people, who succeed better than the non-empathic people do to simulate and recognize the others' emotion, were also more prone to time distortions in a social context. The time distortions in a bisection task featuring emotional facial expressions were indeed greater in high-empathy participants than in low-empathy ones, as assessed by Baron-Cohen's Empathy Quotient (Mondillon, Niedenthal, Gil $\&$ Droit-Volet, 2007). These greater time distortions in empathic people suggest that they better understand the others' intentions and better anticipate 'in time' their reactions. In another study, we demonstrated that emotional facial expressions influence time perception when participants can spontaneously mimic the facial expressions of others, but not when this facial mimicry is impeded by a pen held between the lips (Effron et al., 2006). The mimicry of the facial expression perceived in the other, triggering the simulation of the perceived emotional state, is indeed one of the main mechanisms mediating the understanding of other people (e.g. Dimberg, Thunberg \& Grunedal, 2002). The facial mimicry elicits the associated emotional state, by activating the brain structures underlying that emotion (Adolphs, Damasio, Tranel, 
Cooper \& Damasio, 2000; Decety \& Chaminade, 2003). We can thus assume that individuals embody and memorize other people's emotions and actions, together with their timing.

A temporal bisection study published by our team on the temporal discrimination of pictures of older people yielded further data in support of this hypothesis (Chambon et al., 2005, 2008). In this study, participants viewed pictures of young and older people's faces, all with the same durations, and had to judge whether their durations were more similar to a short or a long anchor duration in the form of a pink oval. The perception of the older faces significantly shifted the psychophysical function toward the right, compared with that of the young faces, indicating that the durations of the older faces were underestimated. A further analysis of data revealed a slope effect, suggesting that this temporal underestimation was linked to a slowing down of the internal clock. This is entirely consistent with studies in social psychology showing that the activation of the 'elderly person' stereotypical trait in memory causes people to walk more slowly (Bargh, Chen \& Burrows, 1996). Within the framework of the theory of grounded time (Droit-Volet, in press; Droit-Volet \& Gil, 2009), these results can be explained by the bodily reenactment of the experience of the slow movements of older people. The embodied simulation of older people's speed of movement therefore seems to be associated with a slowing down of the internal clock which, in turn, has an impact on the subjective estimation of time. Consequently, we suggest that time judgments are directly affected by changes in the body produced by the embodied simulation of other people's rhythms, thus revealing the individuals' capacity to tune themselves to the time of the other.

We do not yet, however, fully understand either the embodiment of timing and its representation in memory, or the nature of its influence on different types of time judgment. In the previous century, philosophers (Bergson, 1968; Guyau, 1890) and pioneering psychologists (Fraisse, 1967) suggested that our sense of time is grounded in our experiences. As we write in Lloyd and Arstila's book on subjective time (in press for 2 years), it is time to seriously reconsider this notion at a scientific level, by analyzing findings on time distortions in the light of results on time perception in humans and other animals that suggest the existence of an internal clock system in the brain. This would open up a whole new avenue of research, with some studies looking for fresh evidence in support of this theory of grounded time and others exploring its limitations. 


\section{References}

Adolphs, R., Damasio, H., Tranel, D., Cooper, G., \& Damasio, A. R. (2000). A role for somatosensory cortices in the visual recognition of emotion as revealed by 3 -D lesion mapping. J. Neurosci., 20, 2683-2690.

American Psychiatric Association (1994). Diagnostic Criteria from the DSM-IV. Washington, DC: American Psychiatric Association.

Anderson, M. J., Reis-Costa, K., \& Misanin, J. R. (2007). Effects of September 11th terrorism stress on estimated duration. Percept. Motor Skill., 104, 799-802.

Angrilli, A., Cherubini, P., Pavese, A., \& Manfredini, S. (1997). The influence of affective factors on time perception. Percept. Psychophys., 59, 972-982.

Balsam, P. D., Drew, M. R., \& Gallistel, C. R. (2010). Time and associative learning. Comp. Cogn. Behav. Rev., 5, 1-22.

Bargh, J. A., Chen, M., \& Burrows, L. (1996). The automaticity of social behaviour: direct effects of trait construct and stereotype activation on action. J. Pers. Soc. Psychol., 71, 230244.

Bar-Haim, Y., Kerem, A., Lamy, D., \& Zakay, D. (2010). When time slows down: the influence of threat on time perception in anxiety. Cogn. Emotion, 24, 255-263.

Barsalou, L. W. (1999). Perceptual symbol system. Behav. Brain Sci., 22, 577-660.

Barsalou, L. W. (2008). Grounded cognition. Ann. Rev. Psychol., 59, 617-645.

Bech, P. (1975). Depression: influence on time estimation and time experiments. Acta Psychiat. Scand., 51, 42-50.

Bergson, H. (1968). Durée et simultanéité. Presses Universitaires de France.

Blewett, A. E. (1992). Abnormal subjective time experience in depression. Brit. J. Psychiat., 161, 195-200.

Bradley, M. M., \& Lang, P. J. (1999). International affective digitized sounds (IADS): stimuli, instruction manual and affective ratings. Technical Report B-2. Gainesville, FL, USA: The Center for Research in Psychophysiology, University of Florida.

Brown, B. L., Richer, P., \& Doyère, V. (2007). The effect of an intruded event on peak-interval timing in rats: isolation of a postcue effect. Behav. Proc., 74, 300-310.

Bschor, T., Ising, M., Bauer, M., Lewitzka, U., Skerstupeit, M., Müller-Oerlinghausen, B., \& Baethge, C. (2004). Time experience and time judgment in major depression, mania and healthy subjects. A controlled study of 93 subjects. Acta Psychiat. Scand., 109, 222-229.

Buetti, S., \& Lleras, A. (2012). Perceiving control over aversive and fearful events can alter how we experience those events: an investigation of time perception in spider-fearful individuals. Front. Psychol., 3, 1-17.

Buhusi, C. V., \& Meck, W. H. (2002). Differential effects of methamphetamine and haloperidol on the control of an internal clock. Behav. Neurosci., 116, 291-297.

Burle, B., \& Casini, L. (2001). Dissociation between activation and attention effects in time estimation: implication for internal clock models. J. Exp. Psychol.: Human Percept. Perform., 27, 195-205.

Campbell, L. A., \& Bryant, R. A. (2007). How time flies: a study of novice skydivers. Behav. Res. Ther., 45, 1389-1392. 
Chambon, M., Droit-Volet, S., \& Niedenthal, P. M. (2008). The effect of embodying the elderly on time perception. J. Exp. Soc. Psychol., 44, 672-678.

Conway, L. G. (2004). Social contagion of time perception. J. Exp. Soc. Psychol., 40, 113-120.

Coull, J. T., Vidal, F., Nazarian, B., \& Macar, F. (2004). Functional anatomy of the attentional modulation of time estimation. Science, 303, 1506-1508.

Coull, J. T., Cheng, R. K., \& Meck, W. H. (2011). Neuroanatomical and neurochemical substrates of timing. Neuropsychopharmacol., 36, 3-25.

Craig, A. D. (2009). Emotional moments across time: a possible neural basis for time perception in the anterior insula. Philos. T. R. Soc. B, 364, 1933-1942.

Damasio, A. R. (1999). The feeling of what happens: body and emotion in the making of consciousness. New York, USA: Harcourt Brace.

Decety, J., \& Chaminade, T. (2003). Neural correlates of feeling sympathy. Neuropsychologia, $41,127-138$.

Dimberg, U., Thunberg, M., \& Grunedal, S. (2002). Facial reactions to emotional stimuli: automatically controlled emotional responses. Cogn. Emotion, 16, 449-471.

Doi, H., \& Shinohara, K. (2009). The perceived duration of emotional face is influenced by the gaze direction. Neurosci. Lett., 457, 97-100.

Droit-Volet, S. (1998). Adaptation to time in young children: an initial force rule governing temporal behavior. J. Exp. Child Psychol., 68, 236-249.

Droit-Volet, S. (2011). Child and time. In A. Vatakis, A. Esposito, M. Giagkou, F. Cummins, \& G. Papdelis (Eds.), Multidisciplinary aspects of time and time perception (pp. 151-173). Berlin Heidelberg: Springer-Verlag.

Droit-Volet, S. (2013a). Time perception, emotions and mood disorders. J. Physiology-Paris, http://dx.doi.org/10.1016/j.jphysparis.2013.03.005.

Droit-Volet, S. (2013b). Time perception in children: a neurodevelopmental approach. Neuropsychologia, 51, 220-234.

Droit-Volet, S. (in press). What emotions tell us about time. In D. Lloyd \& V. Arstila (Eds.), Subjective time: the philosophy, psychology, and neuroscience of temporality. Cambridge, MA, USA: MIT Press.

Droit-Volet, S., \& Rattat, A.-C. (1999). Are time and action dissociated in young children's time estimation? Cogn. Dev., 14, 573-595.

Droit-Volet, S., \& Wearden, J. (2002). Speeding up an internal clock in children? Effects of visual flicker on subjective duration. Quart. J. Exp. Psychol., 55B, 193-211.

Droit-Volet, S., \& Meck, W. H. (2007). How emotions colour our time perception. Trends Cogn. Sci., 1, 504-513.

Droit-Volet, S., \& Gil, S. (2009). The time-emotion paradox. J. Phil. Trans. Royal Soc. B Biol. Sci., 364, 1943-1953.

Droit-Volet, S., Brunot, S., \& Niedenthal, P. M. (2004). Perception of the duration of emotional events. Cogn. Emotion, 18, 849-858.

Droit-Volet, S., Bigand, E., Ramos, D., \& Bueno, J. L. O. (2010a). Time flies with music whatever its emotional valence. Acta Psychol., 135, 226-236.

Droit-Volet, S., Mermillod, M., Cocenas-Silva, R., \& Gil, S. (2010b). The effect of expectancy of a threatening event on time perception in human adults. Emotion, 10, 908-914 [?not cited in text].

Droit-Volet, S., Fayolle, S. L., \& Gil, S. (2011). Emotional state and time perception: mood elicited by films. Front. Integr. Neurosci., 5, 33. 
Effron, D., Niedenthal, P., Gil, S., \& Droit-Volet, S. (2006). Embodied temporal perception of emotion. Emotion, 6, 1-9.

Ekman, P., \& Friesen, W. (1976). Pictures of facial affect. Palo Alto, CA, USA: Consulting Psychologist Press.

Ekman, P., \& Davidson, R. (1994). The nature of emotion: fundamental questions. New York, USA: Oxford University Press.

Falk, J. L., \& Bindra, D. (1954). Judgment of time as a function of serial position and stress. J. Exp. Psychol., 39, 327-331.

Fraisse, P. (1967). Psychologie du temps. Paris, France: Presses Universitaires de France.

Fridlund, A. J. (1997). The new ethology of human facial expressions. In J. A. Russell \& J. M. F. Dols (Eds.), New directions in the study of facial expressions (pp. 103-129). New York, USA: Cambridge University Press.

Frijda, N. H. (2000). The psychologists' point of view. In M. Lewis \& J. M. Haviland-Jones (Eds.), Handbook of emotions (2nd ed., pp. ç-74). New York, USA: Guilford Press.

Frijda, N. H. (2007). The laws of emotion. Mahwah, NJ, USA: Lawrence Erlbaum Associates, Inc.

Fuchs, T. (2001). Melancholia as a desynchronisation. Psychopathology, 34, 179-186.

Gable, P. A., \& Poole, B. D. (2012). Time flies when you're having approach-motivated fun: effects of motivational intensity on time perception. Psychol. Sci. doi:10.1177/ 0956797611435817.

Gallagher, S. (2012). Time, emotion, and depression. Emotion Rev., 4, 1-6.

Gallese, V., Fadiga, L., Fogassi, L., \& Rizzolatti, G. (1996). Action recognition in the premotor cortex. Brain, 119, 593-609.

Gibbon, J. (1977). Scalar expectancy theory and Weber's law in animal timing. Psychological Review, 84, 279-325.

Gibbon, J., Church, R. M., \& Meck, W. H. (1984). Scalar timing in memory. In J. Gibbon \& L. Allan (Eds.), Annals of the New York Academy of Sciences, 423: Timing and time perception (pp. 52-77). New York, USA: New York Academy of Sciences.

Gil, S., \& Droit-Volet, S. (2009). Time perception, depression and sadness. Behav. Proc., 80, $169-176$.

Gil, S., \& Droit-Volet, S. (2011a). How do emotional facial expressions influence our perception of time. In S. Masmoudi, D. Yan Dai, \& A. Naceur (Eds.), Attention, representation and human performance: integration of cognition, emotion and motivation. London, UK: Psychology Press, Taylor \& Francis.

Gil, S., \& Droit-Volet, S. (2011b). Time flies in the presence of angry faces, depending on the temporal task used! Acta Psychol., 136, 354-362.

Gil, S., \& Droit-Volet, S. (2011c). Time perception in response to ashamed faces in children and adults. Scand. J. Psychol., 52, 138-145.

Gil, S., \& Droit-Volet, S. (2012). Emotional time distortions: the fundamental role of arousal. Cogn. Emotion, 26, 847-862.

Gil, S., Niedenthal, P., \& Droit-Volet, S. (2007). Anger and temporal perception in children. Emotion, 7, 219-225. 
Grinker, J., Glucksman, M. L., Hirsch, J., \& Viseltear, G. (1973). Time perception as a function of weight reduction: a differentiation based on age at onset of obesity. Psychosom. Med., 35, 104-111.

Grommet, E. K., Droit-Volet, S., Gil, S., Hemmes, N. S., Baker, A. H., \& Brown, B. (2010). Effects of a fear cue on time estimation in human observers. Behav. Proc., 86, 88-93.

Gualtieri, C. T., Johnson, L. G., \& Benedict, K. B. (2006). Neurocognition in depression: patients on and off medication versus healthy comparison subjects. J. Neuropsychiat. Clin. Neurosci., 18, 217-225.

Guyau, M. (1890). La genèse de l'idée de temps. Paris, France: Felix Alcan.

Hare, R. D. (1963). The estimation of short temporal intervals terminated by shock. J. Clin. Psychol., 19, 378-380.

Harrington, D. L., Zimbelman, J. L., Hinton, S. C., \& Rao, S. M. (2010). Neural modulation of temporal encoding, maintenance, and decision processes. Cerebral Cortex, 20, 1274-1285.

Hawkins, W. L., French, L. C., Crawford, B. D., \& Enzle, M. E. (1988). Depressed affect time and time depression. J. Abnorm. Psychol., 97, 275-280.

Heidegger, H. (1995). L'Etre et le temps. Paris, France: Gallimard (original work published in 1927).

Hoffer, A., \& Osmond, H. (1962). The relationship between mood and time perception. Psychiat. Q. Supp., 36, 87-92.

Ivry, R. B., \& Schlerf, J. E. (2008). Dedicated and intrinsic models of time perception. Trends Cogn. Sci., 12, 273-280.

Kitamura, T., \& Kumar, R. (1982). Time passes slowly for patients with depressive state. Acta Psychol. Scand., 4, 127-140.

Kitamura, T., \& Kumar, R. (1984). Controlled study on time reproduction of depressive patients. Psychopathology, 17, 24-27.

Koster, E. H. W., De Lissnyder, E., Derakshan, N., \& De Raedt, R. (2011). Understanding depressive rumination from a cognitive science perspective: the impaired disengagement hypothesis. Clin. Psychol. Rev., 31,138-145.

Kuhs, H., Hermann, W., Kammer, K., \& Tolle, R. (1991). Time estimation and the experience of time in endogenous depression (Melancholia): an experimental investigation. Psychopathology, 24, 7-11.

Lambrechts, A., Mella, N., Pouthas, V., \& Noulhiane, M. (2011). Subjectivity of time perception: a visual emotional orchestration. Front. Integr. Neurosci., 5(73), 1-6.

Lamotte, M., Izaute, M., \& Droit-Volet, S. (2012). The consciousness of time distortions and their effect on time judgment: a metacognitive approach. Conscious. Cogn., 21, 835-842.

Lang, P. J., Bradley, M. M., \& Cuthbert, B. N. (1999). International affective picture rating system (IAPS): instruction manual and affective ratings. Technical Report A-4. Gainsville, FL, USA: The Centre for Research in Psychophysiology, University of Florida.

Langer, J., Wapner, S., \& Werner, H. (1961). The effect of danger upon the experience of time. Am. J. Psychol., 74, 94-97.

Ledoux, J. E. (2000). Emotion circuits in the brain. Ann. Rev. Neurosci., 23, 155-184.

Ledoux, J. E. (2007). The amygdal. Curr. Biol., 23, 868-874.

Ledoux, J. E. (2012). Rethinking the emotional brain. Neuron, 23, 653-676. 
Lemke, M. R., Koethe, N. H., \& Schleidt, M. (2000). Segmentation of behavior and time structure of movements in depressed patients. Psychopathology, 33, 131-136.

Levin, I. (1979). Interference of time-related and unrelated cues with duration comparison of young children: analysis of Piaget's formulation of the relation of time and speed. Child Dev., 50, 469-477.

Lewis, A. (1932). The experience of time in mental disorder. Proc. Roy. Soc. Med., 25, 611620.

Lewis, P. A., \& Miall, R. C. (2006). Remembering the time: a continuous clock. Trends Cogn. Sci., 10, 401-406.

Loftus, E. F., Schooler, J. W., Boone, S. M., \& Kline, D. (1987). Time went by so slowly: overestimation of event durations by males and females. Appl. Cogn. Psychol., 1, 3-13.

Lui, M. A., Penney, T. B., \& Schirmer, A. (2011). Emotion effects on timing: attention versus pacemaker accounts. PlosOne, 6, e21829.

Maricq, A. V., Roberts, S., \& Church, R. M. (1981). Metamphetamine and time estimation. J. Exp. Psychol.: Animal Behav. Proc., 7, 18-30.

Matell, M. S., \& Meck, W. H. (2000). Neuropsychological mechanisms of interval timing behavior. BioEssays, 22, 94-103.

Matell, M. S., \& Meck, W. H. (2004). Cortico-striatal circuits and interval timing: coincidence detection of oscillatory processes. Cogn. Brain Res., 21, 139-170.

Mauk, M., \& Buonomano, D. (2004). The neural basis of temporal processing. Ann. Rev. Neurosci., 27, 207-340.

Mayer, J. D., \& Gaschke, Y. N. (1988). The experience and meta-experience mood. J. Pers. Soc. Psychol., 55, 102-111.

Meck, W. H. (1983). Selective adjustement of the speed of the clock and memory processes. J. Exp. Psychol.: Animal Behav. Proc., 9, 171-201.

Meck, W. H., \& Macdonald, C. J. (2007). Amygdala inactivation reverses fear's ability to impair divided attention and make time stand still. Behav. Neurosci., 121, 707-720.

Meck, W. H., Penney, T., \& Pouthas, V. (2008). Cortico-striatal representation of time in animals and humans. Curr. Opin. Neurobiol., 18, 145-152.

Mella, N., Conty, L., \& Pouthas, V. (2010). The role of physiological arousal in time perception: 28 psychophysiological evidence from an emotion regulation paradigm. Brain Cogn., 75(2), 182-187.

Mezey, A. G., \& Cohen, S. I. (1961). The effect of depressive illness on time judgment and time experience. J. Neurol. Neurosurg. Ps., 24, 269.

Minkowski, E. (1988). Le temps vécu. Imago Mundi, Chile: Brionne (réedition Delachaux et Niestlé, 1968).

Mondillon, L., Niedenthal, P. M., Gil, S., \& Droit-Volet, S. (2007). Imitation of in-group versus out-group members' facial expressions of anger. A test with a time perception task. Soc. Neurosci., 2, 223-237.

Msetfi, R. M., Murphy, R. A., \& Kornbrot, D. E. (2012). The effect of mild depression on time discrimination. Quart. J. Exp. Psychol., 65, 632-645.

Munzel, K., Gendner, G., Steinberg, R., \& Raith, L. (1988). Time estimation of depressive patients: the influence of interval content. Eur. Arch. Psychiat. Neurol. Sci., 237, 171-178.

Nather, F. C., Bueno, J. L. O., Bigand, E., \& Droit-Volet, S. (2011). Time changes with the embodiment of another's body posture. PlosOne, 6, 1-7. 
Niedenthal, P. M. (2007). Embodying emotion. Science, 316, 1002-1005.

Noulhiane, M., Mella, N., Samson, S., Ragot, R., \& Pouthas, V. (2007). How emotional auditory stimuli modulate time perception. Emotion, 7, 697-704.

Öhman, A., \& Mineka, S. (2001). Fears, phobias, and preparedness: toward an evolved module of fear and fear learning. Psychol. Rev., 108, 483-522.

Öhman, A., \& Soares, J. J. E. (1998). Emotional conditioning to masked stimuli: expectancies for aversive outcomes following nonrecognized fear-relevant stimuli. J. Exp. Psychol.: Gen., 127, 69-82.

Paus, T. (2000). Functional anatomy of arousal and attention systems in the human brain. Prog. Brain Res., 126, 65-77.

Peretz, I., Gagnon, L., \& Bouchard, B. (1998). Music and emotion: perceptual determinants, immediacy and isolation after brain damage. Cognition, 68, 111-141.

Phelps, E. A., \& Ledoux, J. E. (2005). Contributions of the amygdala to emotion processing: from animal models to human behavior. Neuron, 48, 175-187.

Piaget, P. (1946). Le développement de la notion de temps chez l'enfant. Paris, France: Presses Universitaires de France.

Prabhu, G. G., Agrawal, A. K., \& Teja, J. S. (1969). Effect of anxiety and depression on time estimation and judgment. Indian Psychol. Rev., 6, 16-21.

Pulvermüller, F. (2005). Brain mechanism linking language and action. Nature Rev. Neurosci., 6, 576-582.

Rammsayer, T. H. (1990). Temporal discrimination in schizophrenic and affective disorders: evidence for a dopamine-dependent internal clock. Int. J. Neurosci., 53, 111-120.

Rammsayer, T. H. (1993). On dopaminergic modulation of temporal information. Biol. Psychol., 36, 209-222.

Rammsayer, T., \& Vogel, W. (1992). Pharmacological properties of the internal clock underlying time perception in humans. Neuropsychobiology, 26, 71-80.

Ratcliffe, M. (2012). Varieties of temporal experience in depression. J. Med. Philos., 37, 114138.

Rattat, A.-C., \& Droit-Volet, S. (2002). Le transfert d'apprentissage de durée d'action chez le jeune enfant: l'effet facilitateur de la variété des actions? Enfance, 54, 141-153.

Rizzolatti, G., Fadiga, L., Gallese, V., \& Fogassi, L. (1996). Premotor cortex and and the recognition of motor actions. Cogn. Brain Res., 3, 131-141.

Robertson, I. H., \& Garavan, H. (2004). Vigilant attention. In M. S. Gazzaniga (Ed.), The cognitive neurosciences (pp. 563-578). Cambridge, MA, USA: MIT Press.

Schaefer, A., Nils, F., Sanchez, X., \& Philippot, P. (2010). Assessing the effectiveness of a large database of emotion-eliciting films: a new tool for emotion researchers. Cogn. Emotion, 24, 1153-1172.

Sévigny, M.-C., Everett, J., \& Grondin, S. (2003). Depression, attention, and time estimation. Brain Cogn., 53, 351-353.

Shi, Z., Jia, L., \& Müller, H. J. (2012). Modulation of tactile duration judgments by emotional pictures. Front. Integr. Neurosci. doi:10.3389/fnint.2012.00024.

Smith, S. D., McIver, T. A., Di Nella, M. S. J., \& Crease, M. L. (2011). The effects of valence and arousal on the emotional modulation of time perception: evidence for multiple stages of processing. Emotion, 11, 1305-1313.

Stetson, C., Fiesta, M. P., \& Eagleman, D. M. (2007). Does time really slow down during a frightening event? PLosOne, 12, 1-3. 
Straus, E. (1947). Disorders of personal time in depressive states. South. Med. J., 25, 254-259.

Tipples, J. (2008). Negative emotionality influences the effects of emotion on time perception. Emotion, 8, 127-131.

Tipples, J. (2011). When time stands still: fear-specific modulation of temporal bias due to threat. Emotion, 11, 74-80.

Treisman, M. (1963). Temporal discrimination and the indifference interval: implications for a model of the 'internal clock. Psychol. Monogr., 77, 1-13.

Treisman, M., Faulkner, A., Naish, P., \& Brogan, D. (1990). The internal clock: evidence for a temporal oscillator underlying time perception with some estimates of its characteristic frequency. Perception, 19, 705-743.

Tysk, L. (1984). Time perception and affective disorders. Percept. Motor Skill., 58, 455-464.

van Heijnsbergen, C., Meeren, H., Grèzes, J., \& de Gelder, B. (2007). Rapid detection of fear in body expressions, an ERP study. Brain Res., 1186, 233-241.

Vuilleumier, P. (2005). How brains beware: neural mechanisms of emotional attention. Trends Cogn. Sci., 9, 585-594.

Wang, L., \& Yi Jiang, Y. (2012). Life motion signals lengthen perceived temporal duration. Proc. Natl Acad. Sci. USA, 109, E673-E677.

Watkins, E., \& Brown, R. G. (2002). Rumination and executive function in depression: an experimental study. J. Neurol. Neurosurg. Ps., 72, 400-402.

Watts, F. N., \& Sharrock, R. (1984). Fear and time estimation. Percept. Motor Skill., 59, $597-$ 598.

Wearden, J. H. (2008). Slowing down an internal clock: implications for accounts of performance on four timing. Quart. J. Exp. Psychol., 61, 263-274.

Wearden, J. H., Philpott, K., \& Win, T. (1999). Speeding up and (... relatively. . . ) slowing down and internal clock in humans. Behav. Proc., 46, 63-73.

Wiener, M., Turkeltaub, P., \& Coslette, H. B. (2010). The image of time: a voxel-wise metaanalysis. NeuroImage, 49, 1728-1740.

Williamson, L. L., Cheng, R. K., Etchegaray, M., \& Meck, W. H. (2008). Speed' warps time: methamphetamine's interactive roles in drug abuse, habit formation, and the biological clocks of circadian and interval timing. Curr. Drug Abuse Rev., 1, 203-212.

Wittmann, M., Simmons, A. N., Aron, J. L., \& Paulus, M. P. (2010a). Accumulation of neural activity in the posterior insula encodes the passage of time. Neuropsychologia, 48, 3110 3120.

Wittmann, M., van Wassenhove, V., Craig, A. D., \& Paulus, M. P. (2010b). The neural substrates of subjective time dilatation. Front. Human Neurosci., 4, 1-9.

Wyrick, R. A., \& Wyrick, L. C. (1977). Time experience during depression. Arch. Gen. Psychiat., 34, 1441-1443.

Yamada, Y., \& Kawabe, T. (2011). Emotion colors time perceptions unconsciously. Conscious. Cogn., 20, 1835-1841.

Zakay, D., \& Block, R. A. (1996). The role of attention in time estimation processes. In M. A. Pastor \& J. Artieda (Eds.), Time, internal clocks and movement (pp. 143-164). Amsterdam, The Netherlands: Elsevier.

Zuili, N., \& Fraisse, P. (1946). L'estimation du temps en fonction de la quantité de movements effective dans une tâche. Etude génétique. L'Année Psychologique, 66, 383-396. 
Query to the Authors:

1

Please check if " $p s>05$ " (page 20, line 22) was changed to " $p s>0.05$ " 2 correctly. 